\title{
Comprehensive Trends and Patterns of Antihypertensive Prescriptions Using a Nationwide Claims Database in Korea
}

This article was published in the following Dove Press journal: Clinical Epidemiology

\author{
Minji Jung (D) \\ Eunjung Choo (i)* \\ Sukhyang Lee \\ Division of Clinical Pharmacy, College of \\ Pharmacy, Ajou University, Suwon, \\ Republic of Korea \\ *These authors contributed equally to \\ this work
}

Purpose: The number of people receiving antihypertensive prescriptions in Korea has increased more than threefold from 2002 to 2016. However, previous studies regarding the current use of these medications have been fairly limited. We aimed to examine the current trends and changes in the patterns of antihypertensive prescriptions based on a nationwide claims database.

Patients and Methods: Patients receiving antihypertensive medications over 30 days, without any limited therapeutic indication, were identified using the Health Insurance Review and Assessment Service (HIRA) database between 2015 and 2017. For each patient, the use of antihypertensive medication was specified as the class of drug used for the longest duration in each year.

Results: A total of $8,625,821$ patients in 2015, 8,997,829 patients in 2016, and 9,357,751 patients in 2017 taking antihypertensives were included in this study. Angiotensin II receptor blockers (ARB) $(35.9 \%$ in 2015 and $38.9 \%$ in 2017) and calcium channel blockers (CCB) (37.1\% in 2015 and $35.2 \%$ in 2017) for monotherapy, $\mathrm{ARB}+\mathrm{CCB}$ combinations $(49.3 \%$ in 2015 and $56.3 \%$ in 2017) for dual therapy, and $\mathrm{ARB}+\mathrm{CCB}+$ diuretics combinations $(48.8 \%$ in 2015 and $48.9 \%$ in 2017) for more than triple therapy were the most frequently prescribed. Subjects aged $\geq 70$ showed the highest prescription rate of antihypertensives compared with those $<70$; however, a decreasing trend presented from $62.3 \%$ in 2015 to $54.2 \%$ in 2017 . Additionally, in subjects aged $>70$ years, the rate in women was higher than that in men, but this was reversed in younger patients. While changes arose in the patterns of the use of antihypertensives, these were similar each year.

Conclusion: The trends and changes in the patterns of the use of antihypertensive medications were affected by age, sex, and type of therapy. Our findings may contribute to a better understanding of the actual status regarding the use of antihypertensive medications in Korea.

Keywords: antihypertensive medications, drug utilization study, nationwide claims database

\section{Introduction}

Hypertension is one of the most important risk factors for cardiovascular and cerebrovascular diseases, ${ }^{1,2}$ which are the leading causes of mortality worldwide, including in Korea. ${ }^{3,4}$ The prevalence of hypertension is about $29.1 \%$ among the Korean population over the age of 30. The costs attributable to hypertension have been estimated at $\$ 240$ million, accounting for $13.4 \%$ of the total medical costs for all chronic disorders. ${ }^{5}$
Correspondence: Sukhyang Lee Division of Clinical Pharmacy, College of Pharmacy, Ajou University, 206 WorldcupRo Yeongtong-Gu, Suwon 16499, Republic of Korea

Tel +82-3I-219-3443

Fax +82-31-219-3435

Email suklee@ajou.ac.kr
Clinical Epidemiology 2020:12 963-975 
In Korea, the number of people receiving antihypertensive drugs has increased more than threefold between 2002 (2.5 million) and 2016 (8.2 million). ${ }^{6}$ In the Eighth Joint National Committee (JNC 8) guidelines for the management of hypertension in adults, four classes of antihypertensive medications, including angiotensin II receptor blockers (ARB), angiotensin-converting enzyme inhibitors (ACEI), calcium channel blockers (CCB), and diuretics (DU), are used as first-line therapies for the treatment of hypertensive patients. ${ }^{7}$ Antihypertensive medication usually is initiated with a single drug at a low dose in patients without target organ complications, and an increased dose or combined use with a second drug is recommended when the first-line treatment is not sufficiently effective. ${ }^{8}$ However, guideline recommendations are not always applied in daily clinical practice. ${ }^{9}$ Approximately $56 \%$ of patients with hypertension do not achieve targets for blood pressure control. ${ }^{6}$

Antihypertensive medications have diverse indications, including cardiac or kidney diseases in addition to hypertension. ${ }^{10}$ However, the trends of antihypertensive prescriptions, without any limited conditions such as the indication of hypertension, have not been fully examined. ${ }^{6,11}$ Moreover, previous studies comprehensively describing the modifications of patterns for antihypertensive medications remain limited. ${ }^{12,13}$ Of these, a retrospective study of antihypertensive drugs for lowering blood pressure examined a transition in prescription patterns but only focused on the addition of drugs to first-line antihypertensive drug classes. ${ }^{12}$

To understand the use of antihypertensive medications in Korea comprehensively, we aimed to examine trends and changes in the patterns of the use of antihypertensive medications in a Korean nationwide claims-based study.

\section{Patients and Methods}

\section{Data Source and Study Populations}

We used the Health Insurance Review and Assessment Service (HIRA) database in Korea between 2015 and 2017. The Korean National Health Insurance Service (NHIS) enrolls more than $97 \%$ of the entire Korean population. ${ }^{14}$ The HIRA database contains healthcare information of almost the entire Korean population, consisting of approximately 50 million people, as a social insurance benefits system that can be used for epidemiological studies. ${ }^{15}$ However, because administrative insurance data are not collected for research, data cleaning, and manipulation are required. For the present study, data cleaning involved procedures of handling the missing, erroneous, or duplicated values, and standardizing the format of raw data to fit our study design. Data manipulation included procedures such as confirming the study database and establishing and applying definitions of drug use. These processes are used to increase transparency and improve the repeatability and reproducibility of published results (Figure S1). ${ }^{16}$

In this study, the following data were available from the HIRA database: (1) patient information, including age and sex; (2) date of the clinic and hospital visit records for prescribing medications; and (3) prescription information, including prescribed drug codes, quantity, route of administration, single administration doses, prescription dates, and total daily dosage of antihypertensive medications.

From the HIRA database, patients who have taken oral antihypertensive medications over 30 days without any limited therapeutic indications including hypertension, were included on a yearly basis between 2015 and 2017 (Figure 1). Patients who were disqualified for health coverage reasons, such as emigration or death were not included. A detailed list of the codes is presented in Table S1.

Before providing the data, HIRA removed the confidential and identifying information of all patients to protect their privacy. Thus, this study was exempt from acquiring patient informed consent due to the encrypted identification of all patient information. The study protocol was approved by the institutional review board of Ajou University (IRB No. 201905-HB-EX-001), and official approval was obtained from the HIRA research inquiry commission (No. M20190507713).

\section{Study Outcomes}

The study outcomes were the trends and changes in the patterns of the use of antihypertensive medication between 2015 and 2017. The trends of antihypertensive prescriptions were assessed annually according to age, sex, and type of therapy. Changes in the patterns of antihypertensive drug use were investigated and compared with those of the previous year (2016 vs 2015; 2017 vs 2016).

The use of antihypertensive medication for each patient was specified as the class of drug used for the longest duration in each year (2015-2017). Days of prescription, defined as the sum of supply days for a prescription, were calculated as the average number of the duration. Antihypertensive medications were assigned by year to three types of therapy: monotherapy, dual combination therapy, and triple or more combination therapy. Monotherapy was defined as the use of one class of antihypertensive medication: ACEI, ARB, beta-blockers (BB), $\mathrm{CCB}$, DU, or alpha-blockers or vasodilators (OTHER). Combination therapy was defined as concomitantly using 

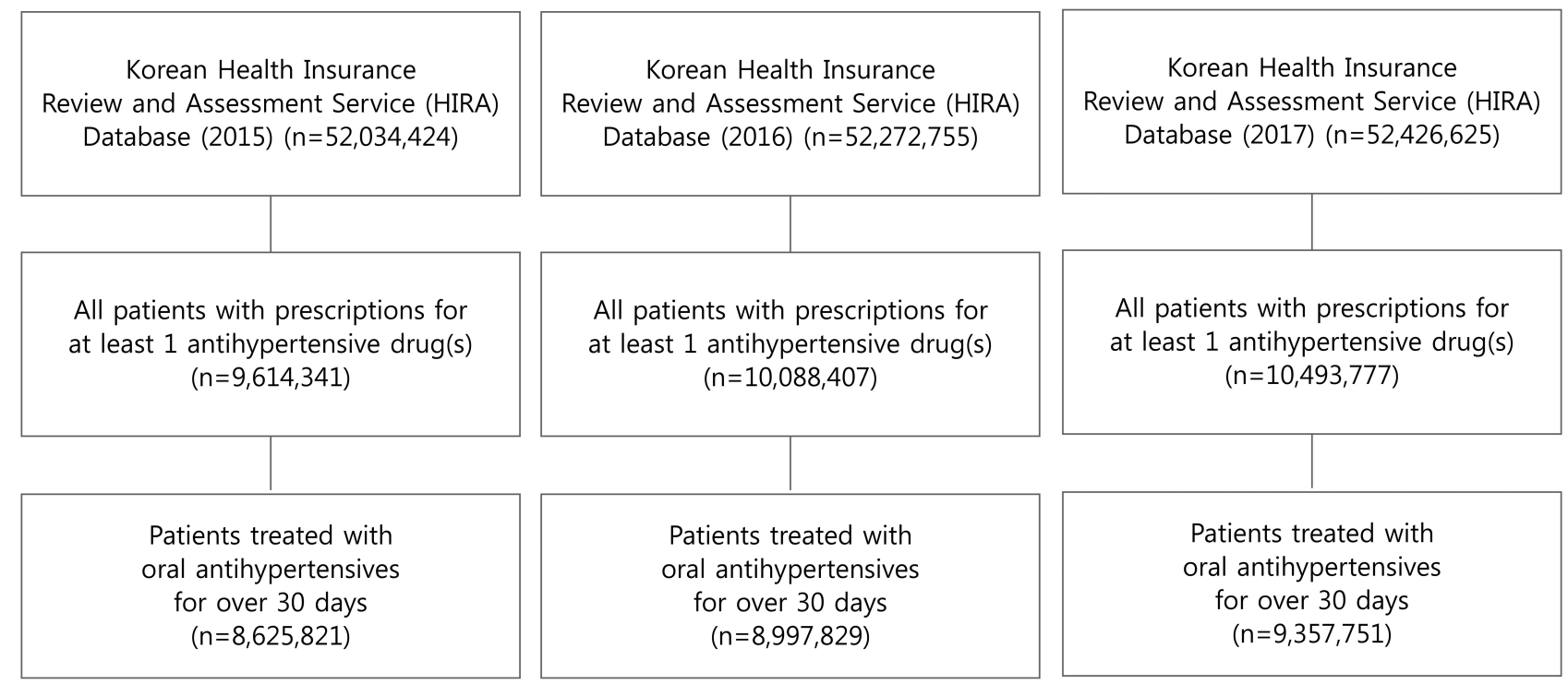

Figure I The flowchart for patient selection.

Notes: Of the entire population of 50 million Koreans, patients who have taken oral antihypertensive medications over 30 days without any limited therapeutic indications including hypertension, were included on a yearly basis between 2015 and 2017.

two or more classes of antihypertensive drugs regardless of fixed-dose or a free-dose combination. If the date of prescriptions for different drugs overlapped over 14 days, we assumed that the overlapping was caused by combination therapy. Otherwise, the overlapping was considered caused by switching medications. Frequently used combination therapies based on our study-defined method were designated to several groups, shown in Table S2.

To identify changes in the patterns of drug use compared with those of the previous year, we tracked each patient and for year to year analysis. Five categorized groups were identified as follows: (1) Consistent, continued the same therapy; (2) Switch, changed one or both medications to different classes; (3) Add-on, added one or more other drug classes to the existing therapy; (4) Drop-off, dropped at least one class from the existing therapy; and (5) Quit, dropped all classes from the existing therapy, and retained no use of antihypertensive medications the following year. Thus, with monotherapy, drop-off and quit were the same.

\section{Statistical Analysis}

Baseline characteristics were summarized using descriptive statistics and presented as frequencies and percentages of patients, days of prescription, or as means with the standard deviation (SD). Descriptive statistics were evaluated for age, sex, and the use of antihypertensive medications. Age was categorized into four groups, as follows: <30, 30-49, 50-69, and $\geq 70$ years.

Additionally, the prescription rate of antihypertensive medications among the entire insured Korean population, stratified by age groups, was estimated to evaluate the prescription magnitude of the drugs. The prescription rate was calculated as the number of patients with antihypertensives divided by the total number of insured people per age stratification. The data for total populations enrolled in the NHIS were available from the Korean Statistical Information Service (KOSIS) (www.

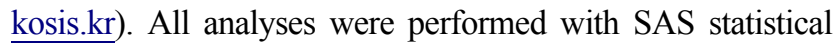
software (version 9.4. for Windows; SAS Institute, Inc., Cary, NC, USA).

\section{Results}

\section{Baseline Characteristics}

Among a total of 9,614,341 patients in 2015, 10,088,407 patients in 2016, and 10,493,777 patients in 2017 treated with at least one antihypertensive drug, 8,625,821 in $2015,8,997,829$ in 2016, and 9,357,751 in 2017 were identified as study subjects after applying the inclusion criteria. The mean (SD) age of the patients was 62.6 (13.17) years in 2015, 61.9 (13.18) years in 2016, and 61.2 (13.18) years in 2017. The male users were 50.5\% in $2015,50.1 \%$ in 2016 , and $49.8 \%$ in 2017 . The mean days of prescription were 280 in 2015, 282 in 2016, and 284 in 2017 (Table 1). 


\section{Trends and Patterns of Antihypertensive}

\section{Prescriptions}

Trends of Antihypertensive Prescriptions

Trends of the use of antihypertensive medications were similar for each year from 2015 to 2017. Monotherapy subjects accounted for $43.9 \%$ and $44.0 \%$ of all subjects in 2015 and 2017, respectively, followed by dual therapy (39.9\% and $40.7 \%)$ and more than triple therapy $(16.2 \%$ and $15.2 \%)$ subjects. In this study, ARB (35.9\% and
$38.9 \%)$ and $\mathrm{CCB}(37.1 \%$ and $35.2 \%)$ for monotherapy, $\mathrm{ARB}+\mathrm{CCB}$ combination (49.3\% and $56.3 \%$ ) for dual therapy, and $\mathrm{ARB}+\mathrm{CCB}+\mathrm{DU}$ combination ( $48.8 \%$ and $48.9 \%)$ for more than triple therapy for 2015 and 2017, respectively, were the most frequently prescribed (Table 1).

Table 2 and Figure 2 summarize the number of patients prescribed antihypertensives, and this was stratified by sex and age in 2017. Overall, among subjects $<30$ years, monotherapy accounted for the highest portion of

Table I Characteristics of Patients Prescribed Antihypertensive Medications

\begin{tabular}{|c|c|c|c|c|c|c|c|c|c|}
\hline \multirow[b]{2}{*}{$\begin{array}{l}\text { Baseline } \\
\text { Characteristics }\end{array}$} & \multicolumn{3}{|l|}{2015} & \multicolumn{3}{|l|}{2016} & \multicolumn{3}{|l|}{2017} \\
\hline & $\mathbf{n}$ & (\%) & $\begin{array}{l}\text { Days of } \\
\text { Prescription }\end{array}$ & $\mathbf{n}$ & (\%) & $\begin{array}{l}\text { Days of } \\
\text { Prescription }\end{array}$ & $\mathbf{n}$ & (\%) & $\begin{array}{l}\text { Days of } \\
\text { Prescription }\end{array}$ \\
\hline Overall & $8,625,821$ & & 280.4 & $8,997,829$ & & 281.6 & $9,357,751$ & & 283.5 \\
\hline \multicolumn{10}{|l|}{ Sex } \\
\hline Male & $4,266,354$ & 49.46 & 277.0 & $4,487,34 I$ & 49.87 & 278.5 & $4,701,919$ & 50.25 & 280.6 \\
\hline Female & $4,359,467$ & 50.54 & 283.7 & $4,510,488$ & 50.13 & 284.7 & $4,655,832$ & 49.75 & 286.4 \\
\hline \multicolumn{10}{|l|}{ Age } \\
\hline$($ mean $\pm S D)$ & \multicolumn{3}{|c|}{$62.6 \pm 13.17$} & \multicolumn{3}{|c|}{$61.9 \pm 13.18$} & \multicolumn{3}{|c|}{$61.2 \pm 13.18$} \\
\hline$\leq 29$ & 95,864 & 1.11 & 175.3 & 114,410 & 1.27 & 177.2 & 132,678 & 1.42 & 180.5 \\
\hline $30-49$ & $1,227,862$ & 14.23 & 246.1 & $1,395,642$ & $|5.5|$ & 250.5 & I,565,263 & 16.73 & 255.0 \\
\hline $50-69$ & $4,480,879$ & 51.95 & 286.9 & $4,734,568$ & 52.62 & 288.8 & $4,975,873$ & 53.17 & 291.3 \\
\hline$\geq 70$ & $2,821,216$ & 32.71 & 288.6 & $2,753,209$ & 30.60 & 289.4 & $2,683,937$ & 28.68 & 290.6 \\
\hline \multicolumn{10}{|l|}{ Therapy } \\
\hline Monotherapy & $3,784,922$ & 43.88 & 264.9 & $3,968,468$ & 44.10 & 266.7 & $4,120,642$ & 44.03 & 268.8 \\
\hline ACEI & 73,258 & 1.94 & 289.4 & 69,031 & 1.74 & 292.3 & 65,056 & 1.58 & 293.4 \\
\hline ARB & I,357,496 & 35.87 & 275.7 & I,49I,687 & 37.59 & 278.6 & $\mathrm{I}, 60 \mathrm{I}, 524$ & 38.87 & 282.7 \\
\hline BB & 581,052 & 15.35 & 226.1 & 614,326 & 15.48 & 225.1 & 648,223 & 15.73 & 223.7 \\
\hline $\mathrm{CCB}$ & $\mathrm{I}, 405,383$ & 37.13 & 287.8 & $\mathrm{I}, 427,729$ & 35.98 & 289.1 & $\mathrm{I}, 448,204$ & 35.15 & 290.1 \\
\hline DU & 218,623 & 5.78 & 187.1 & 222,670 & 5.61 & 186.7 & 220,759 & 5.36 & 188.4 \\
\hline OTHER & 149,110 & 3.94 & 203.1 & 143,025 & 3.60 & 208.2 & 136,876 & 3.32 & 212.0 \\
\hline Dual therapy & $3,439,692$ & 39.88 & 291.1 & $3,619,328$ & 40.22 & 292.2 & $3,8 \mid 2,327$ & 40.74 & 294.1 \\
\hline$A R B+B B$ & $|28,9| \mid$ & 3.75 & 295.0 & 136,777 & 3.78 & 295.7 & 144,700 & 3.80 & 298.4 \\
\hline$A R B+C C B$ & $\mathrm{I}, 694,283$ & 49.26 & 288.3 & $1,910,619$ & 52.79 & 290.0 & $2,145,694$ & 56.28 & 292.0 \\
\hline$A R B+D U$ & 934,638 & 27.17 & 290.7 & 930,591 & 25.71 & 291.8 & 914,994 & 24.00 & 295.0 \\
\hline $\mathrm{BB}+\mathrm{CCB}$ & 227,483 & 6.61 & 307.37 & 215,137 & 5.94 & 308.3 & 205,974 & 5.40 & 308.0 \\
\hline $\mathrm{BB}+\mathrm{DU}$ & 99,633 & 2.90 & 283.7 & 97,287 & 2.69 & 282.8 & 94,770 & 2.49 & 281.9 \\
\hline $\mathrm{CCB}+\mathrm{DU}$ & 193,824 & 5.63 & 299.1 & 176,653 & 4.88 & 300.3 & 161,927 & 4.25 & 300.3 \\
\hline $3+$ Classes therapies & $\mathrm{I}, 40 \mathrm{I}, 207$ & 16.24 & 296.0 & $\mathrm{I}, 4 \mathrm{I} 0,033$ & 15.67 & 296.5 & $\mathrm{I}, 424,782$ & 15.23 & 297.6 \\
\hline$A R B+B B+C C B$ & 211,485 & 15.09 & 295.1 & 227,583 & 16.14 & 296.0 & 244,131 & 17.13 & 297.6 \\
\hline $\begin{array}{l}A R B+B B+C C B \\
+D U\end{array}$ & 158,409 & 11.31 & 294.9 & 160,049 & 11.35 & 295.3 & 163,356 & 11.47 & 296.0 \\
\hline$A R B+B B+D U$ & 132,253 & 9.44 & 293.5 & $13 \mid, 054$ & 9.29 & 293.7 & 129,954 & 9.12 & 294.0 \\
\hline$A R B+C C B+D U$ & 683,223 & 48.76 & 298.5 & 688,949 & 48.86 & 299.1 & 696,381 & 48.88 & 300.4 \\
\hline
\end{tabular}

Abbreviations: ARB, angiotensin II receptor blockers; ACEI, angiotensin-converting enzyme inhibitors; BB, beta blockers; CCB, calcium channel blockers; DU, diuretics; OTHER, alpha-blockers or vasodilators. 


\begin{tabular}{|c|c|c|c|c|}
\hline 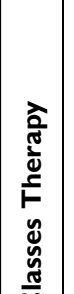 & 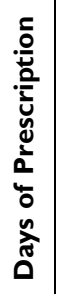 & 我岕 芯 芯 & 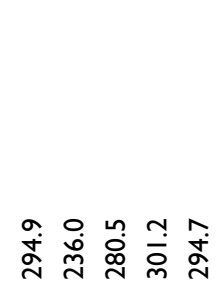 & 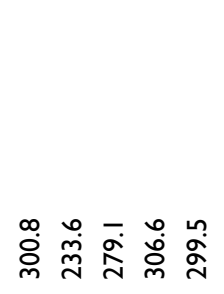 \\
\hline 产 & @ & 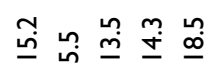 & 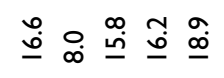 & 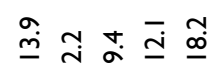 \\
\hline 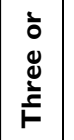 & s & 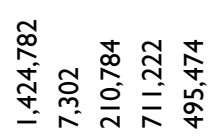 & 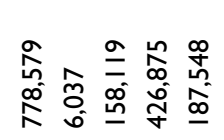 & 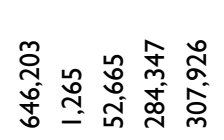 \\
\hline \multirow{3}{*}{ 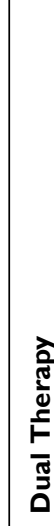 } & 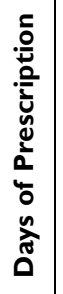 & 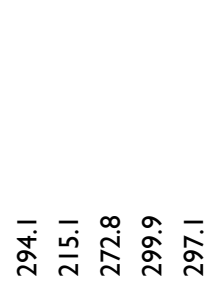 & 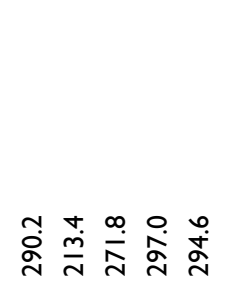 & 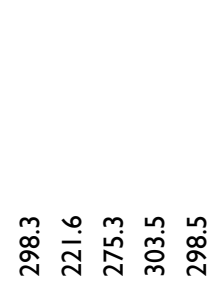 \\
\hline & @ & 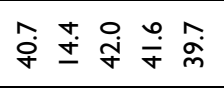 & 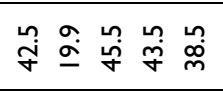 & 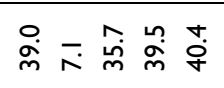 \\
\hline & $=$ & 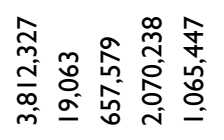 & 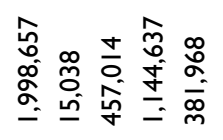 & 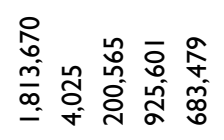 \\
\hline \multirow{3}{*}{ 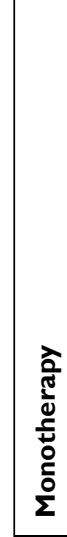 } & 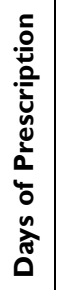 & 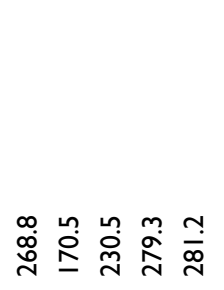 & 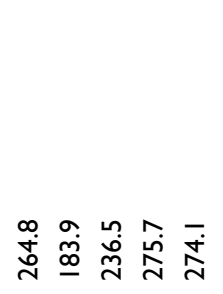 & 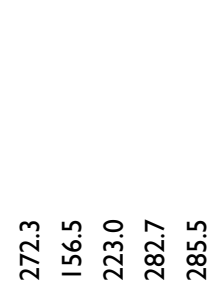 \\
\hline & @ & 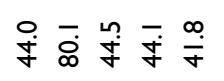 & 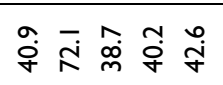 & 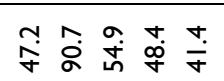 \\
\hline & = & 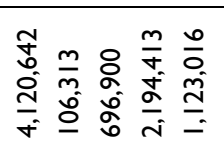 & 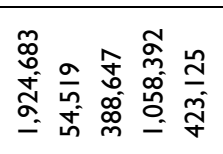 & 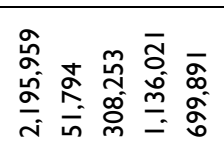 \\
\hline & 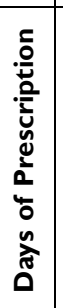 & 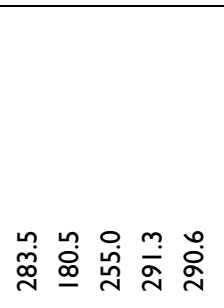 & 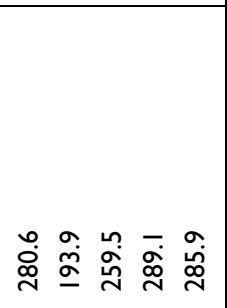 & 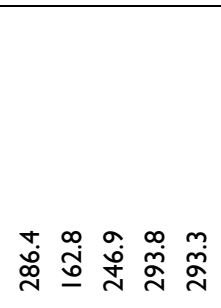 \\
\hline & ๑ & 웅 응 응 응 & 웅 용 응 응 & 웅요 응 응 \\
\hline مّ & $=$ & 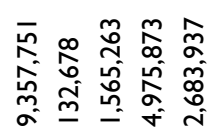 & 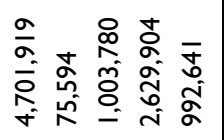 & 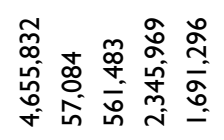 \\
\hline ลั. & & 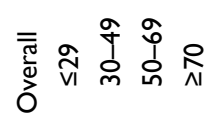 & 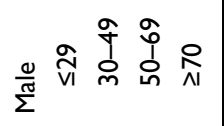 & 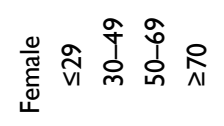 \\
\hline
\end{tabular}


$3,000,000$

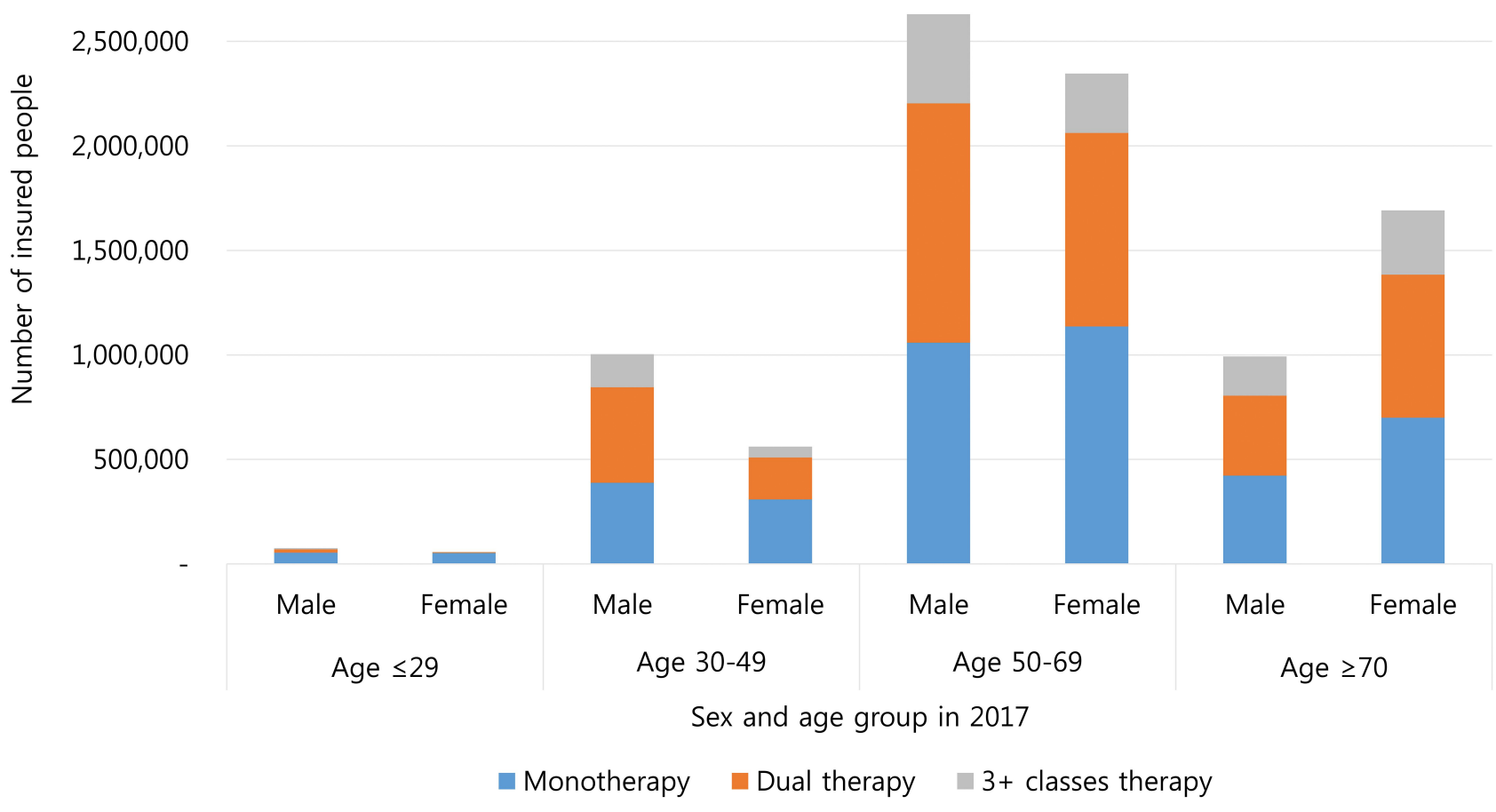

Figure 2 Prescription trends of antihypertensive therapies stratified by sex and age in 2017

Notes: After stratification by sex and age in 2017 , patients prescribed antihypertensive medications were shown. In contrast with participants $<70$ years, women $>70$ years were more likely to receive antihypertensive medications than men $>70$ years.

treatments $(80.1 \%)$. Among those $>30$, monotherapy and dual therapy each accounted for about $40 \%$. After stratification by sex, in contrast with participants $<70$ years, women $>70$ years were more likely to receive antihypertensive medications than men $>70$ years. Data in 2015 and 2016 are supplied in Table S3 and Figure S2.

Trends of antihypertensive medication use were assessed based on the age distribution of the entire insured Korean population using data from KOSIS (Table 3 and Figure 3). An overall increasing trend in antihypertensive prescriptions was observed in the Korean population from 2015 (16.6\%) to 2017 (17.8\%). Subjects aged $\geq 70$ showed the highest prescription rate of antihypertensives compared with those $<70$ years; however, a decreasing trend presented from $62.3 \%$ in 2015 to $54.2 \%$ in 2017 .

Additionally, similar distributions of antihypertensive medication use per age group are shown from 2015 to 2017 in Figure 4 and Table S4. In 2017, approximately $55 \%$ of the patients $>30$ years old were prescribed combination therapies. An increasing trend in CCB use was observed with increasing age from $4.9 \%$ in subjects $<30$ years to $19.1 \%$ in those $\geq 70$ years. By contrast, BB monotherapy was the most frequently prescribed (55.1\%) among those $<30$, and a decreasing trend in BB use $(4.2 \%$ for $>70$ ) was found with increasing age.

\section{Changes in the Patterns of Antihypertensive Prescriptions}

We studied changes in the patterns of antihypertensive medication use compared with the previous year between 2015 and 2017. In 2017 compared with 2016, although most patients continued their therapy across all classes, patients taking BB $(49.8 \%)$, DU $(40.0 \%)$, or OTHER (49.2\%) monotherapies were less persistent than those taking ARB (69.2\%), ACEI (66.2\%), or CCB (71.3\%). Moreover, ARB (31.6\%) accounted for the highest proportion of the add-on group, followed by CCB (22.0\%). In the switch group $\mathrm{ARB}+\mathrm{DU}(17.9 \%)$ combinations accounted for the largest proportion, followed by CCB (17.0\%). Within the drop-off group, patients taking $\mathrm{ARB}+\mathrm{CCB}$ $(23.2 \%)$ combinations or $\mathrm{BB}(22.0 \%)$ were more likely to drop-off or quit (Table 4 and Figure 5). The analysis for 2016 compared with 2015 showed nearly the same results (Table S5 and Figure S3). 
Table 3 Prescription Rates of Antihypertensive Medications Stratified by Sex and Age Compared to Total Insured Koreans Using Data from KOSIS Between 2015 and 2017

\begin{tabular}{|c|c|c|c|c|c|c|c|c|c|}
\hline \multicolumn{10}{|l|}{2015} \\
\hline & \multicolumn{3}{|l|}{ Overall } & \multicolumn{3}{|l|}{ Male } & \multicolumn{3}{|l|}{ Female } \\
\hline & $\begin{array}{l}\text { Insured } \\
\text { Koreans }\end{array}$ & $\begin{array}{l}\text { Study } \\
\text { Patients }\end{array}$ & \multirow[b]{2}{*}{ (\%) } & $\begin{array}{l}\text { Insured } \\
\text { Koreans }\end{array}$ & $\begin{array}{l}\text { Study } \\
\text { Patients }\end{array}$ & \multirow[b]{2}{*}{ (\%) } & $\begin{array}{l}\text { Insured } \\
\text { Koreans }\end{array}$ & $\begin{array}{l}\text { Study } \\
\text { Patients }\end{array}$ & \multirow[b]{2}{*}{ (\%) } \\
\hline & $\mathbf{n}$ & $\mathbf{n}$ & & $\mathbf{n}$ & $\mathbf{n}$ & & $\mathbf{n}$ & $\mathbf{n}$ & \\
\hline Overall & $52,034,424$ & $8,625,821$ & 16.6 & $26,065,615$ & $4,266,354$ & 16.4 & $25,968,809$ & $4,359,467$ & 16.8 \\
\hline$\leq 29$ & $17,230,127$ & 95,864 & 0.6 & $9,006,020$ & 54,079 & 0.6 & $8,224,107$ & 41,785 & 0.5 \\
\hline $30-59$ & $16,790,845$ & $1,227,862$ & 7.3 & $8,585,934$ & 785,970 & 9.2 & $8,204,911$ & 441,892 & 5.4 \\
\hline $50-69$ & $13,482,688$ & $4,480,879$ & 33.2 & $6,696,700$ & $2,370,741$ & 35.4 & $6,785,988$ & $2,110,138$ & 31.1 \\
\hline$\geq 70$ & $4,530,764$ & $2,821,216$ & 62.3 & $|, 776,96|$ & $\mathrm{I}, 055,564$ & 59.4 & $2,753,803$ & $1,765,652$ & 64.1 \\
\hline \multicolumn{10}{|l|}{2016} \\
\hline & \multicolumn{3}{|l|}{ Overall } & \multicolumn{3}{|l|}{ Male } & \multicolumn{3}{|l|}{ Female } \\
\hline & Insured Koreans & Study Patients & & Insured Koreans & Study Patients & & Insured Koreans & Study Patients & \\
\hline & $\mathrm{n}$ & $\mathrm{n}$ & (\%) & $\mathrm{n}$ & $\mathrm{n}$ & $(\%)$ & $\mathrm{n}$ & $\mathrm{n}$ & (\%) \\
\hline Overall & $52,272,755$ & $8,997,829$ & 17.2 & $26,174,820$ & $4,487,341$ & 17.1 & $26,097,935$ & $4,510,488$ & 17.3 \\
\hline$\leq 29$ & $17,029,530$ & 114,410 & 0.7 & $8,896,080$ & 65,032 & 0.7 & $8,133,450$ & 49,378 & 0.6 \\
\hline $30-59$ & $16,627,475$ & $1,395,642$ & 8.4 & $8,495,040$ & 894,478 & 10.5 & $8,132,435$ & 501,164 & 6.2 \\
\hline $50-69$ & $13,9 \mid 4,167$ & $4,734,568$ & 34 & $6,924,234$ & $2,503,388$ & 36.2 & $6,989,933$ & $2,231,180$ & 31.9 \\
\hline$\geq 70$ & $4,70 I, 583$ & $2,753,209$ & 58.6 & $1,859,466$ & $1,024,443$ & 55.1 & $2,842,117$ & $\mathrm{I}, 728,766$ & 60.8 \\
\hline \multicolumn{10}{|l|}{2017} \\
\hline & \multicolumn{3}{|l|}{ Overall } & \multicolumn{3}{|l|}{ Male } & \multicolumn{3}{|l|}{ Female } \\
\hline & Insured Koreans & Study Patients & & Insured Koreans & Study Patients & & Insured Koreans & Study Patients & \\
\hline & $\mathrm{n}$ & $\mathrm{n}$ & (\%) & $\mathrm{n}$ & $\mathrm{n}$ & (\%) & $\mathrm{n}$ & $n$ & $(\%)$ \\
\hline Overall & $52,426,625$ & $9,357,751$ & 17.8 & $26,239,673$ & $4,701,919$ & 17.9 & $26,186,952$ & $4,655,832$ & 17.8 \\
\hline$\leq 29$ & $16,774,628$ & 132,678 & 0.8 & $8,760,955$ & 75,594 & 0.9 & $8,013,673$ & 57,084 & 0.7 \\
\hline $30-59$ & $|6,405| 4 \mid$, & $1,565,263$ & 9.5 & $8,391,948$ & $\mathrm{I}, 003,780$ & 12 & $8,013,193$ & 561,483 & 7 \\
\hline $50-69$ & $14,29 \mid, 613$ & $4,975,873$ & 34.8 & $7,106,986$ & $2,629,904$ & 37 & $7,184,627$ & $2,345,969$ & 32.7 \\
\hline$\geq 70$ & $4,955,243$ & $2,683,937$ & 54.2 & I,979,784 & 992,641 & 50.1 & $2,975,459$ & $1,691,296$ & 56.8 \\
\hline
\end{tabular}

Abbreviation: KOSIS, Korean Statistical Information Service.

\section{Discussion}

In this study, trends and changes in the patterns of antihypertensive prescriptions were identified among the entire Korean population using the nationwide HIRA claims database. Because we focused on the comprehensive use of antihypertensive medications, we included all subjects who were treated with the medications regardless of their therapeutic indications. Among the six classes of antihypertensive drugs, ARB and CCB were the most commonly prescribed between 2015 and 2017. The trends of antihypertensive medication use were affected by patient age, sex, and type of therapy. While there were changes in the patterns between years, these were similar within the study period.

Our findings are consistent with those of a previous study in Korea that reported ARB (51.6\%) and CCB $(45.0 \%)$ were the most frequently prescribed classes of drugs regardless of monotherapy or combination therapy in patients diagnosed with hypertension. ${ }^{11}$ We also found that $\mathrm{ARB}$ and $\mathrm{CCB}$ for monotherapy, $\mathrm{ARB}+\mathrm{CCB}$ combinations for dual therapy, and $\mathrm{ARB}+\mathrm{CCB}+\mathrm{DU}$ combinations for triple therapy or more were the most frequently prescribed medications. These results are in line with those of a previous study involving Japanese patients with 


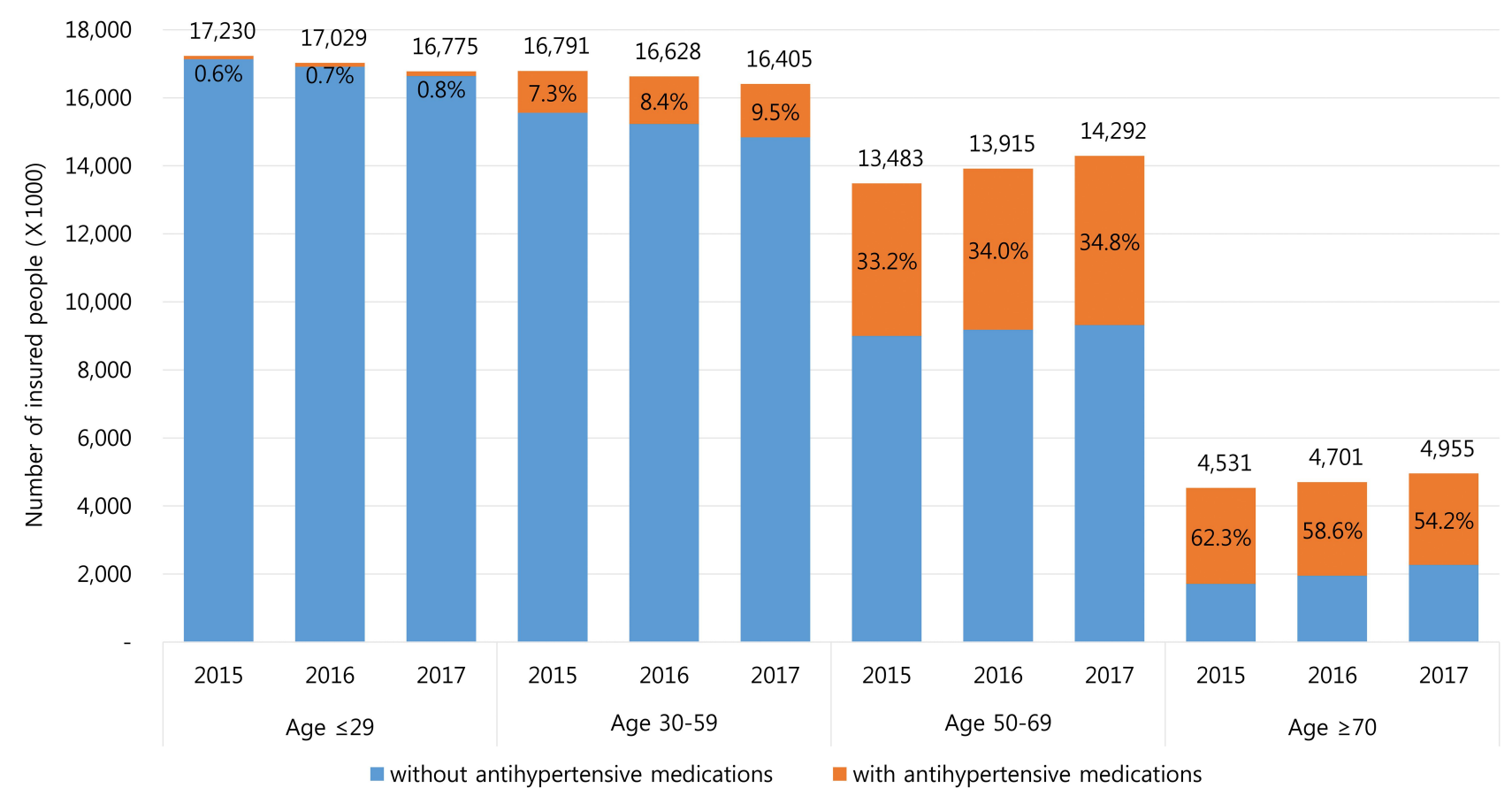

Figure 3 Prescription rates of antihypertensive medications stratified by year and age compared to total insured Koreans using data from KOSIS.

Notes: The number of insured people by Korea's National Health Insurance for every year was shown on the top of each bar according to age. The red portion of each bar was the prescription rate of antihypertensive medications and the blue portion of each bar was the proportion of people without antihypertensive medications. The prescription rate of antihypertensive medications among the entire insured Korean population, stratified by age groups, was estimated to evaluate the prescription magnitude of the drugs. The prescription rate was calculated as the number of patients with antihypertensives divided by the total number of insured people per age stratification. Subjects aged $\geq 70$ showed the highest prescription rate of antihypertensives compared with those $<70$ years; however, a decreasing trend presented from $62.3 \%$ in 2015 to $54.2 \%$ in 2017 .

Abbreviation: KOSIS, Korean Statistical Information Service.

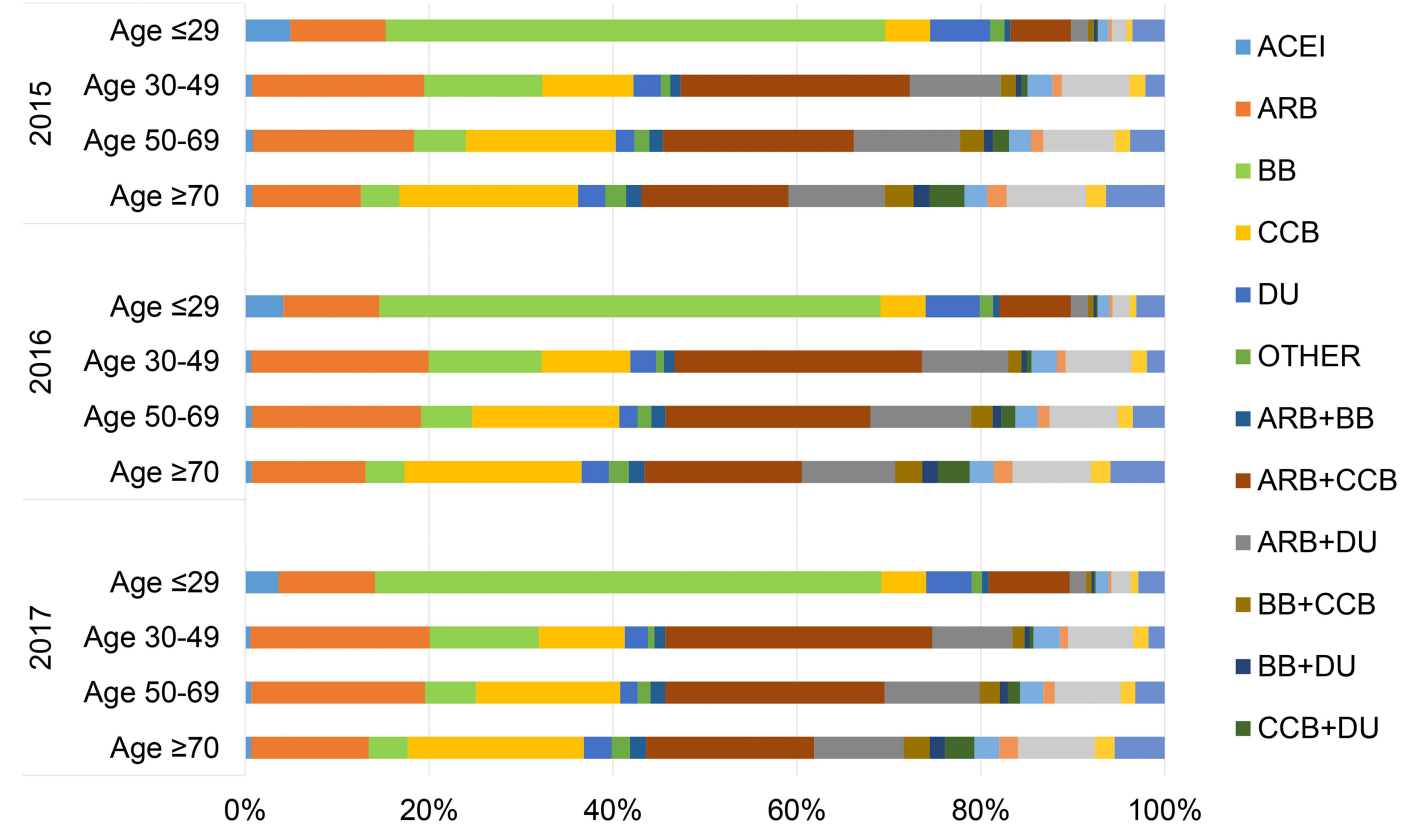

Figure 4 Distribution of age and prescription of antihypertensive medications presented by $100 \%$ stacked row graphs.

Notes: Other: alpha-blockers or vasodilators. In 2017, an increasing trend in CCB use was observed with increasing age from $4.9 \%$ in subjects $<30$ years to $19.1 \%$ in those $\geq 70$ years. By contrast, BB monotherapy was the most frequently prescribed $(55.1 \%)$ among those $<30$, and a decreasing trend in $\mathrm{BB}$ use $(4.2 \%$ for $>70)$ was found with increasing age. The similar distributions of antihypertensive medication use per age group were shown from 2015 to 2017.

Abbreviations: ACEl, angiotensin-converting enzyme inhibitors; ARB, angiotensin II receptor blockers; BB, beta blockers; CCB, calcium channel blockers; DU, diuretics. 
Table 4 Drug Class Proportion of Pattern Change Compared to the Previous Year (2017 vs 2016)

\begin{tabular}{|c|c|c|c|c|c|c|c|c|c|c|c|}
\hline \multirow[t]{2}{*}{ Year } & \multirow[t]{2}{*}{ Therapy } & \multicolumn{2}{|c|}{ Consistent } & \multicolumn{2}{|l|}{ Add-On } & \multicolumn{2}{|l|}{ Switch } & \multicolumn{2}{|c|}{ Drop-Off } & \multicolumn{2}{|l|}{ Quit } \\
\hline & & $\mathbf{n}$ & (\%) & $\mathbf{n}$ & (\%) & $\mathbf{n}$ & (\%) & $\mathbf{n}$ & (\%) & $\mathbf{n}$ & (\%) \\
\hline \multirow[t]{18}{*}{2017 vs 2016} & Overall & $6,936,978$ & & 520,668 & & 386,162 & & 443,860 & & 710,161 & \\
\hline & ACEI & 50,687 & 0.7 & 3,057 & 0.6 & 8,926 & 2.3 & & & 6,361 & 0.9 \\
\hline & ARB & $|| 83,,94 \mid$ & 17.1 & 164,732 & 31.6 & 41,676 & 10.8 & & & 101,338 & 14.3 \\
\hline & BB & 405,273 & 5.8 & 24,879 & 4.8 & 27,734 & 7.2 & & & 156,440 & 22.0 \\
\hline & $\mathrm{CCB}$ & $\mathrm{I},|\mathrm{I}|, 077$ & 16.4 & 114,659 & 22.0 & 65,773 & 17.0 & & & 106,220 & 15.0 \\
\hline & DU & 117,925 & 1.7 & 12,998 & 2.5 & 12,472 & 3.2 & & & 79,275 & 11.2 \\
\hline & OTHER & 89,597 & 1.3 & 4,343 & 0.8 & 6,921 & 1.8 & & & 42,164 & 5.9 \\
\hline & $A R B+B B$ & 98,067 & 1.4 & 12,203 & 2.3 & 8,324 & 2.2 & 12,297 & 2.8 & 5,886 & 0.8 \\
\hline & $\mathrm{ARB}+\mathrm{CCB}$ & I,595,868 & 23.0 & 88,190 & 16.9 & 43,117 & 11.2 & 103,136 & 23.2 & 80,308 & 11.3 \\
\hline & $A R B+D U$ & 720,290 & 10.4 & 34,592 & 6.6 & 69,130 & 17.9 & 65,174 & 14.7 & 41,405 & 5.8 \\
\hline & $\mathrm{BB}+\mathrm{CCB}$ & 166,262 & 2.4 & 9,497 & 1.8 & 16,029 & 4.2 & 14,996 & 3.4 & 8,353 & 1.2 \\
\hline & $\mathrm{BB}+\mathrm{DU}$ & 68,021 & 1.0 & 3,895 & 0.7 & 7,763 & 2.0 & 8,083 & 1.8 & 9,525 & 1.3 \\
\hline & $\mathrm{CCB}+\mathrm{DU}$ & $130,4 \mid 9$ & 1.9 & 7,945 & 1.5 & 14,106 & 3.7 & 13,753 & 3.1 & 10,430 & 1.5 \\
\hline & $A R B+B B+C C B$ & $|7|, 284$ & 2.5 & 10,388 & 2.0 & 8,032 & 2.1 & 29,582 & 6.7 & 8,297 & 1.2 \\
\hline & $A R B+B B+D U$ & 93,438 & 1.3 & 4,463 & 0.9 & 9,737 & 2.5 & 17,224 & 3.9 & 6,192 & 0.9 \\
\hline & $A R B+C C B+D U$ & 541,653 & 7.8 & 12,803 & 2.5 & 12,452 & 3.2 & 99,311 & 22.4 & 22,730 & 3.2 \\
\hline & $\mathrm{ARB}+\mathrm{BB}+\mathrm{CCB}+\mathrm{DU}$ & 119,822 & 1.7 & 954 & 0.2 & 865 & 0.2 & 32,558 & 7.3 & 5,850 & 0.8 \\
\hline & etc. & 243,354 & 3.5 & 11,070 & 2.1 & 33,105 & 8.6 & 47,746 & 10.8 & 19,387 & 2.7 \\
\hline
\end{tabular}

hypertension that evaluated the prescription status of $\mathrm{ARB}$ as a first-line drug. ${ }^{17}$ Although we did not have information on diagnoses, similarities between these studies suggest that almost all of our subjects were presumably diagnosed with hypertension. In 2016, 8.9 million people had hypertension, ${ }^{6}$ and our study included approximately 9 million patients treated with antihypertensive medications in 2016. Additionally, our findings are similar to those of a Korean hypertension factsheet of 2018 (involving patients with hypertension $>30$ years old) that contained the same definitions of medication use as ours. In the factsheet, the most common classes were ARB (43.3\%) and $\mathrm{CCB}(42.9 \%)$; the combination of $\mathrm{ARB}$ $+\mathrm{CCB}$ regimens was the most frequently used (53.9\%); and dual therapy accounted for $42.1 \%$, followed by monotherapy $(40.3 \%)$ and more than triple therapy $(17.7 \%)^{6}$

$\mathrm{ARB}$ and $\mathrm{CCB}$ are the most common antihypertensive medications in Asia, including China and Japan, ${ }^{12,18}$ which is similar to our results. The JNC 8 guidelines and Korean hypertension guidelines recommend ARB, CCB, and DU as the first-line treatment. ${ }^{7,8}$ A worldwide increase in prescriptions for $\mathrm{ARB}$ and $\mathrm{CCB}$ has been identified over the past several years. ${ }^{19}$ This increase may be related to the increased prevalence of compelling indications such as chronic kidney disease (CKD) or diabetes during the study period. $^{20,21}$ In Korea, CKD patients increased from
170,576 to 203,978 , and the related medical cost also increased from $\$ 1.25$ billion to $\$ 1.44$ billion between 2015 and 2017. Additionally, the prevalence of diabetes also increased in Korea from $11.4 \%$ in 2015 to $14.4 \%$ in 2016. Moreover, the increase in these prescriptions could be associated with their blood pressure-lowering, organprotective, and cardiovascular event-lowering effects ${ }^{22}$ with more favorable adherence. ${ }^{23,24} \mathrm{CCB}$ is one of the most popular antihypertensive classes, because of its ability to lower blood pressure, efficacy to vascular resistance, and minor side effects. ${ }^{25,26}$ Furthermore, the combination of $\mathrm{ARB}+\mathrm{CCB}$ is a commonly used regimen because of the improved effects of lowering blood pressure ${ }^{27-29}$ and reduced potential side effects, including edema caused by $\mathrm{CCB} .{ }^{30}$ Additionally, many fixed-dose combinations of $\mathrm{ARB}+\mathrm{CCB}$ are available, as several pharmaceutical companies in Korea have developed them. The preference and availability of these drug shave contributed to ARB and $\mathrm{CCB}$ being the most frequently prescribed antihypertensive drug classes.

Although DU and ACEI are suggested as major classes for the treatment of hypertension or other indications, the usage rates of these medications were lower than those in the United States and when compared with ARB and CCB. These may be associated with their side effects, including hypokalemia for $\mathrm{DU}^{31}$ and dry cough for ACEI, in Asian 


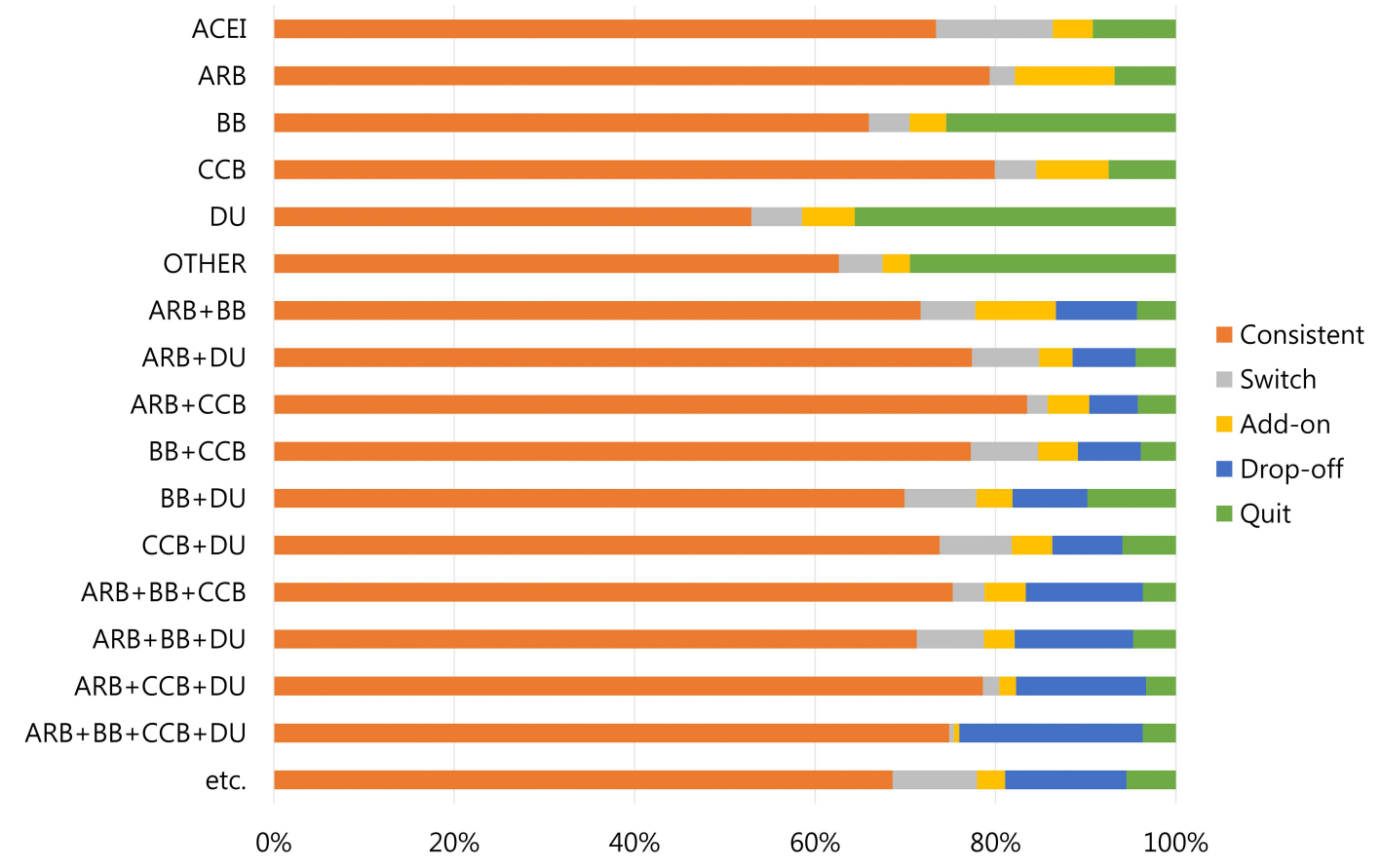

Figure 5 Changes in the pattern of antihypertensive medications presented by 100\% stacked row graphs compared to the previous year in 2017 vs 2016. Notes: Other: alpha-blockers or vasodilators. While changes arose in the patterns of antihypertensive medication use during the study period, they were similar from year to year. The treatment change in each patient was tracked and analyzed from year to year. Five categorized groups were identified as follows: (I) Consistent, continued the same therapy; (2) Switch, changed one or both medications to different classes; (3) Add-on, added one or more other drug classes to the existing therapy; (4) Drop-off, dropped at least one class from the existing therapy; and (5) Quit, dropped all classes from the existing therapy, and retained no use of antihypertensive medications the following year. Thus, with monotherapy, drop-off and quit were the same.

Abbreviations: ACEI, angiotensin-converting enzyme inhibitors; ARB, angiotensin II receptor blockers; BB, beta blockers; CCB, calcium channel blockers; DU, diuretics.

populations. ${ }^{32}$ Decreased rates of ACEI use may be caused by the increase in ARB use. ${ }^{33}$ Moreover, a previous study also reported a similar trend of increasing ARB and decreasing DU in Korea. ${ }^{34}$ Therefore, combination therapies involving ACEI were not be designated as the top ten most frequently used combination therapies in our study.

The present study included subjects treated with antihypertensives irrespective of whether they had been previously used or newly started. The proportions of people taking combination therapy were $56.1 \%$ in $2015,55.9 \%$ in 2016 , and $56.0 \%$ in 2017 , respectively. These findings are consistent with that of a previous study, which reported that $50.9 \%$ of patients were already taking combination therapy. ${ }^{34}$ By contrast, the proportions were higher than those among drug-naïve patients $(33.3 \%) .{ }^{11}$

In the present study, subjects $\geq 70$ years old showed the highest antihypertensive prescription rate in the entire population of insured Koreans using data from KOSIS. However, the prescription rates in patients $>70$ years have decreased between 2015 and 2017, in contrast with the data for patients $<70$. This may be attributable to the extended healthy life expectancy of elderly people with better medical services and a greater interest in health. The World Health Organization reported that a healthy life expectancy at 60 years of age increased in Korea from 19.4 years to 19.7 years between 2015 and 2016, respectively. ${ }^{35}$ However, the interpretation of this association should be carefully applied in practice because of the short-term study period. Furthermore, the changes in blood pressure goals for the elderly population have become more lenient (SBP $<150 \mathrm{mmHg}$ in JNC 8), which may partially explain the decrease in the drug use within this population. ${ }^{7}$ Interestingly, in patients $>70$ years, the prescription rate of antihypertensive medications in women was higher than that in men, which was reversed in subjects $<70$ years (Figure S4). This may be because blood pressure increases significantly in women after menopause and needs to be controlled in those with hypertension. ${ }^{36}$

In our study, the trends for the use of antihypertensives varied according to age group. The use of $\mathrm{CCB}$ consistently increased with age, whereas that of $\mathrm{BB}$ decreased with age. A recent study showed similar findings in Korea. ${ }^{11}$ The increase in the use of $\mathrm{CCB}$ with age may be associated with the ability of $\mathrm{CCB}$ to lower arterial 
stiffness in the elderly. ${ }^{37,38}$ However, BB is not recommended as the first-line therapy for hypertension without compelling indications, such as congestive heart failure and ischemic heart disease. ${ }^{39}$ We found that the use of BB was generally low, but BB was more frequently used in patients $<30$ years compared with other age groups. The reduction in the use of $\mathrm{BB}$ with age may be related to the finding that the benefits of $\mathrm{BB}$ may not outweigh their risks in the elderly. ${ }^{40} \mathrm{BB}$ has documented safety and effectiveness in children and adolescents. ${ }^{41,42}$ Additionally, the preferential use of certain classes of drugs for underlying conditions, such as heart disease or migraine, may affect the use of $\mathrm{BB}$ in a younger population. ${ }^{43}$ Moreover, our findings may be associated with younger patients being more likely to receive monotherapies compared with older patients.

The use of antihypertensive medications in general practice includes initiating, titrating, adding, or switching drugs with different mechanisms to control blood pressure. $^{7}$ In this study, we investigated changes in the patterns of antihypertensive prescriptions compared with the previous year from 2015-2017; 2016 vs 2015 and 2017 vs 2016. Although we were unable to estimate the changes during a single year, changes in the patterns between years were similar because these drugs are generally prescribed for chronic diseases. The finding that ARB and CCB accounted for the major proportion of the add-on group supports the guideline recommendations concerning first-line treatments. Most classes were likely to be in a group following consistent compliance, but BB, DU, and OTHER were identified more in the quit group than others. Although we were unable to determine the indication for why each drug was prescribed, these findings may be related to the indications of those medications, such as edema or acute heart failure, rather than hypertension as a short-term use for acute treatment.

Our study has several strengths. First, to the best of our knowledge, our study was the first to identify the trends and changes in the patterns of antihypertensive prescriptions among the entire population of 50 million Koreans. Because these drugs are indicated for arrhythmia, congestive heart failure, ischemic heart disease, and CKD, in addition to hypertension, ${ }^{10}$ we included all patients receiving antihypertensive medications with all therapeutic indications to reflect the real-world health care situation. Second, we performed this study by developing a claimsbased algorithm of data cleaning and manipulation to improve the transparency and reliability of our results.
However, there are several limitations to our study. First, although the HIRA database is well established for population-based studies, it had no available data for variables, such as laboratory tests and vital signs, due to the nature of claims and reimbursement data. Second, hypertension guidelines are more specific regarding subtypes of CCB and DU such as dihydropyridine CCB and thiazidelike DU, respectively. However, because we mainly focused on the use of the classes of antihypertensive drugs, we did not divide these into subtypes. Third, patient information, including diagnosis data and provider data, could not be evaluated due to the size restriction of providing HIRA data workspace. Accordingly, we could not identify the detailed information related to concomitant diseases of the study population. However, in reference to a prior Korean study, which showed similar results to the trend of antihypertensive medication use, we expect that the comorbidities of dyslipidemia, diabetes mellitus, or both may account for $31.9 \%, 7.8 \%$, or $17.1 \%$, respectively. ${ }^{6}$ Also, we could assume that the prevalence of ischemic stroke, heart failure, arrhythmia and CKD could be $1.71 \%, 1.53 \%, 0.7 \%$, and $3.0 \%$, respectively. ${ }^{4-}$ ${ }^{47}$ Fourth, the inclusion criteria of the study patients which were not restricted to initiators only may have influenced the results regarding the high rates of continuation across all classes, because new users are likely to drop or change drugs. Finally, we did not apply a statistical trend analysis with only three years (2015-2017) due to the potential for misleading or under-powered data. ${ }^{48,49}$ Although the short-term study period may be insufficient to assess the trends and changes in the patterns of antihypertensives, our study was the first to estimate the latest prescribed information among the entire population of Koreans. Despite these limitations, our findings may contribute to a better understanding of the actual status of the use of antihypertensive medications in Korea.

\section{Conclusion}

We identified the trends and patterns of the use of antihypertensive medications using a nationwide claims database every year from 2015 to 2017. The trends of antihypertensive prescriptions were affected by patient age, sex, and type of therapy. While changes arose in the patterns of antihypertensive medication use, they were similar from year to year. Further analyses are needed to identify the clinical characteristics of antihypertensive medication users in the entire Korean population. 


\section{Acknowledgments}

This research was supported by a grant (19172MFDS141) from Ministry of Food and Drug Safety in 2019.

\section{Disclosure}

The authors report no conflicts of interest in this work.

\section{References}

1. Lopez AD, Mathers CD, Ezzati M, Jamison DT, Murray CJ. Global and regional burden of disease and risk factors, 2001: systematic analysis of population health data. The Lancet. 2006;367 (9524):1747-1757. doi:10.1016/S0140-6736(06)68770-9

2. Feigin VL, Roth GA, Naghavi M, et al. Global burden of stroke and risk factors in 188 countries, during 1990-2013: a systematic analysis for the Global Burden of Disease Study 2013. The Lancet Neurol. 2016;15(9):913-924. doi:10.1016/S1474-4422(16)30073-4

3. Levenson JW, Skerrett PJ, Gaziano JM. Reducing the global burden of cardiovascular disease: the role of risk factors. Prev Cardiol. 2002;5(4):188-199. doi:10.1111/j.1520-037X.2002.00564.X

4. Lee K, Park J. Burden of disease in Korea during 2000-10. J Public Health (Bangkok). 2014;36(2):225-234. doi:10.1093/pubmed/fdt056

5. Lee SW, Lee H-Y, Ihm SH, Park SH, Kim TH, Kim HC. Status of hypertension screening in the Korea National General Health Screening Program: a questionnaire survey on 210 screening centers in two metropolitan areas. Clin Hypertension. 2017;23(1):23. doi:10.1186/s40885-017-0075-z

6. Kim HC, Cho M-C. Korea hypertension fact sheet 2018. Clin Hypertension. 2018;24(1):1-4. doi:10.1186/s40885-018-0098-0

7. Armstrong C. JNC8 guidelines for the management of hypertension in adults. Am Fam Physician. 2014;90(7):503-504.

8. Lee H-Y, Shin J, Kim G-H, et al. 2018 Korean Society of Hypertension Guidelines for the management of hypertension: part II-diagnosis and treatment of hypertension. Clin Hypertension. 2019;25(1):20. doi:10.1186/s40885-019-0124-x

9. Grol R, Grimshaw J. From best evidence to best practice: effective implementation of change in patients' care. The Lancet. 2003;362 (9391):1225-1230. doi:10.1016/S0140-6736(03)14546-1

10. Jackson R, Bellamy M. Antihypertensive drugs. Continuing Educ Anaesthesia Crit Care Pain. 2015;15(6):280-285.

11. Kim SH, Shin DW, Kim S, et al. Prescribing Patterns of antihypertensives for treatment-naïve patients in South Korea: from Korean NHISS claim data. Int J Hypertens. 2019;2019.

12. Ohishi M, Yoshida T, Oh A, et al. Analysis of antihypertensive treatment using real-world Japanese data-the retrospective study of antihypertensives for lowering blood pressure (REAL) study. Hypertension Res. 2019;42(7):1057-1067. doi:10.1038/s41440-0190238-2

13. Ishida T, Oh A, Hiroi S, Shimasaki Y, Nishigaki N, Tsuchihashi T. Treatment patterns and adherence to antihypertensive combination therapies in Japan using a claims database. Hypertension Res. 2019;42(2):249-256. doi:10.1038/s41440-018-0127-0

14. Lee J, Lee JS, Park S-H, Shin SA, Kim K. Cohort profile: the national health insurance service-national sample cohort (NHIS-NSC), South Korea. Int J Epidemiol. 2017;46(2):e15-e15. doi:10.1093/ije/dyv319

15. Kim J, Yoon S, Kim L-Y, Kim D-S. Towards actualizing the value potential of Korea Health Insurance Review and Assessment (HIRA) data as a resource for health research: strengths, limitations, applications, and strategies for optimal use of HIRA data. J Korean Med Sci. 2017;32(5):718-728. doi:10.3346/jkms.2017.32.5.718

16. Van den Broeck J, Cunningham SA, Eeckels R, Herbst K. Data cleaning: detecting, diagnosing, and editing data abnormalities. PLoS Med. 2005;2:10. doi:10.1371/journal.pmed.0020267
17. Hiroi S, Shimasaki Y, Kikuchi T, Otsuka Y, Iwasaki K, Ohishi M. Analysis of second-and third-line antihypertensive treatments after initial therapy with an angiotensin II receptor blocker using real-world Japanese data. Hypertension Res. 2016;39(12):907-912. doi:10.1038/hr.2016.96

18. Xu H, He Y, Xu L, Yan X, Dai H. Trends and patterns of five antihypertensive drug classes between 2007 and 2012 in China using hospital prescription data. Int $J$ Clin Pharmacol Ther. 2015;53(6):430-437. doi:10.5414/CP202243

19. Jarari N, Rao N, Peela JR, et al. A review on prescribing patterns of antihypertensive drugs. Clin Hypertension. 2015;22(1):7. doi:10.1186/s40885-016-0042-0

20. Kim B-Y, Won JC, Lee JH, et al. Diabetes Fact Sheets in Korea, 2018: an appraisal of current status. Diabetes Metab J. 2019;43 (4):487-494. doi:10.4093/dmj.2019.0067

21. The Korean Society of Nephrology (KSN). Chronic kidney disease Fact Sheet in Korea. 2018. Available from: http://www.ksn.or.kr/rang_board/ list.html?num=1570\&code=factsheet. Accessed September 2018.

22. Lindholm LH, Ibsen H, Dahlöf B, et al. Cardiovascular morbidity and mortality in patients with diabetes in the Losartan Intervention For Endpoint reduction in hypertension study (LIFE): a randomised trial against atenolol. The Lancet. 2002;359(9311):1004-1010. doi:10.1016/S0140-6736(02)08090-X

23. Omboni S, Volpe M. Angiotensin receptor blockers versus angiotensin converting enzyme inhibitors for the treatment of arterial hypertension and the role of olmesartan. Adv Ther. 2019;36(2):278-297. doi: 10.1007/s12325-018-0859-x

24. Ah Y-M, Lee J-Y, Choi Y-J, et al. Persistence with antihypertensive medications in uncomplicated treatment-naïve patients: effects of initial therapeutic classes. $J$ Korean Med Sci. 2015;30 (12):1800-1806. doi:10.3346/jkms.2015.30.12.1800

25. Zanchetti A, Bond MG, Hennig M, et al. Calcium antagonist lacidipine slows down progression of asymptomatic carotid atherosclerosis: principal results of the European Lacidipine Study on Atherosclerosis (ELSA), a randomized, double-blind, long-term trial. Circulation. 2002;106(19):2422-2427. doi:10.1161/01. CIR.0000039288.86470.DD

26. Lin Y, Ma L. Blood pressure lowering effect of calcium channel blockers on perioperative hypertension: a systematic review and meta-analysis. Medicine. 2018;97:48. doi:10.1097/MD.0000000000013152

27. Kim-Mitsuyama S, Ogawa H, Matsui K, Jinnouchi T, Jinnouchi H, Arakawa K. Differential effectiveness of ARB plus CCB therapy and high-dose ARB therapy in high-risk elderly hypertensive patients: subanalysis of the OSCAR study. Hypertension Res. 2015;38 (3):199-207. doi:10.1038/hr.2014.164

28. Bakris GL. Combined therapy with a calcium channel blocker and an angiotensin II type 1 receptor blocker. $J$ Clin Hypertens. 2008;10:27-32. doi:10.1111/j.1524-6175.2007.08029.x

29. Boutouyrie P, Achouba A, Trunet P, Laurent S. Amlodipine-valsartan combination decreases central systolic blood pressure more effectively than the amlodipine-atenolol combination: the EXPLOR study. Hypertension. 2010;55(6):1314-1322. doi:10.1161/ HYPERTENSIONAHA.109.148999

30. Saruta T, Ogihara T, Saito I, et al. Comparison of olmesartan combined with a calcium channel blocker or a diuretic in elderly hypertensive patients (COLM Study): safety and tolerability. Hypertension Res. 2015;38(2):132-136. doi:10.1038/hr.2014.141

31. Kohro T, Yamazaki T, Sato H, Ohe K, Nagai R. The impact of a change in hypertension management guidelines on diuretic use in Japan: trends in antihypertensive drug prescriptions from 2005 to 2011. Hypertension Res. 2013;36(6):559-563. doi:10.1038/ hr.2012.216

32. McDowell SE, Coleman JJ, Ferner R. Systematic review and meta-analysis of ethnic differences in risks of adverse reactions to drugs used in cardiovascular medicine. BMJ. 2006;332 (7551):1177-1181. doi:10.1136/bmj.38803.528113.55 
33. Investigators $\mathrm{O}$. Telmisartan, ramipril, or both in patients at high risk for vascular events. $N$ Engl J Med. 2008;358(15):1547-1559.

34. Lim B, Kang E, Yoo S-H, Sunwoo S. Utilization pattern of antihypertensive medications according to comorbidities in a hospital-based family medicine practice. Korean J Fam Pract. 2017;7(4):563-568. doi:10.21215/kjfp.2017.7.4.563

35. World Health Organization (WHO) Life expectancy and Healthy life expectancy data by country; 2018. Available from: https://apps.who. int/gho/data/view.main.SDG2016LEXv?lang=en. Accessed April 6, 2018.

36. Park JK, Lim Y-H, Kim K-S, et al. Changes in body fat distribution through menopause increase blood pressure independently of total body fat in middle-aged women: the Korean National Health and Nutrition Examination Survey 2007-2010. Hypertension Res. 2013;36(5):444-449. doi:10.1038/hr.2012.194

37. Janić M, Lunder M, Šabovič M. Arterial stiffness and cardiovascular therapy. Biomed Res Int. 2014;2014.

38. Morgan T. Effect of different antihypertensive drug classes on central aortic pressure. Am J Hypertens. 2004;17(2):118-123. doi:10.1016/j. amjhyper.2003.09.012

39. Sung Y-N, Jang S-M, Lim D-H, Shin S-Y, Song H-J, Lee S-H. Prescribing patterns of antihypertensive drugs by outpatients with hypertension in 2007. Korean J Clin Pharm. 2009;19(2):167-179.

40. Vögele A, Johansson T, Renom-Guiteras A, et al. Effectiveness and safety of beta blockers in the management of hypertension in older adults: a systematic review to help reduce inappropriate prescribing. BMC Geriatr. 2017;17(1):224. doi:10.1186/s12877-017-0575-4

41. Falkner B, Daniels SR, Flynn JT, et al. The fourth report on the diagnosis, evaluation, and treatment of high blood pressure in children and adolescents. Pediatrics. 2004;114(2III):555-576.
42. Riley M, Bluhm B. High blood pressure in children and adolescents. Am Fam Physician. 2012;85(7):693-700.

43. Chobanian AV, Bakris GL, Black HR, et al. The seventh report of the joint national committee on prevention, detection, evaluation, and treatment of high blood pressure: the JNC 7 report. JAMA. 2003;289(19):2560-2571. doi:10.1001/jama.289.19.2560

44. Lee JH, Lim N-K, Cho M-C, Park H-Y. Epidemiology of heart failure in Korea: present and future. Korean Circ J. 2016;46(5):658-664. doi: $10.4070 / \mathrm{kcj} .2016 .46 .5 .658$

45. Lee S-R, Choi E-K. Prevalence of atrial fibrillation in Korean population. Int J Arrhythmia. 2017;18(4):195-204. doi:10.18501/ arrhythmia.2017.030

46. Kim JY, Kang K, Kang J, et al. Executive summary of stroke statistics in Korea 2018: a report from the Epidemiology Research Council of the Korean Stroke Society. J Stroke. 2019;21(1):42. doi:10.5853/jos.2018.03125

47. Statistics KH. Korea National Health and Nutrition Examination Survey. 2017; Available from: http://knhanes.cdc.go.kr/. Accessed August 20, 2020.

48. White ER. Minimum time required to detect population trends: the need for long-term monitoring programs. BioScience. 2019;69 (1):40-46. doi:10.1093/biosci/biy144

49. McCain C, Szewczyk T, Bracy Knight K. Population variability complicates the accurate detection of climate change responses. Glob Chang Biol. 2016;22(6):2081-2093. doi:10.1111/gcb.13211
Clinical Epidemiology

\section{Publish your work in this journal}

Clinical Epidemiology is an international, peer-reviewed, open access, online journal focusing on disease and drug epidemiology, identification of risk factors and screening procedures to develop optimal preventative initiatives and programs. Specific topics include: diagnosis, prognosis, treatment, screening, prevention, risk factor modification,

Submit your manuscript here: https://www.dovepress.com/clinical-epidemiology-journal

\section{Dovepress}

systematic reviews, risk \& safety of medical interventions, epidemiology \& biostatistical methods, and evaluation of guidelines, translational medicine, health policies \& economic evaluations. The manuscript management system is completely online and includes a very quick and fair peer-review system, which is all easy to use. 